\title{
REPRESENTATIONS AND MEANINGS OF ADULT EDUCATION STAFF EVALUATION. A PEDAGOGICAL REFLECTION ON SIX CASE STUDIES
}

\author{
Cristina Palmieri \\ University of Milan Bicocca, Italy
}

\begin{abstract}
This paper deals with six case studies of evaluation, which were discussed at the Mobility Workshop organized in the context of the EduEval Project (Evaluation for the Professional Development of Adult Education Staff, LLP Grundtvig). This paper depicts the different representations of evaluation explicitly and implicitly present. The aim of the article is twofold. First, it explores the meanings associated with the evaluation practices described, and it identifies both transversal and specific components. Second, it critically reflects on how evaluation may sustain and/or develop the competences of Adult Education Staff, in the light of the current pedagogical debate on the theme.
\end{abstract}

Keywords: Adult Education, Evaluation, Evaluation of Adult Education Staff, Evaluation Meanings, Individual Learning, Organizational Learning, Learning through Experience.

\section{Introduction}

Ensuring good quality adult education services, with a special regard for socially, economically or culturally disadvantaged citizens, has been a key objective for the European Union since 2000. The economic and social crisis has made this objective an even more strategic one, thus prompting a tan even sharper focus on the conditions required to facilitate the adult education services in the promotion of lifelong learning and social inclusion (CEU, 2000; 2008; 2011; Striano, 2010). The evaluation of adult education staff is one of these conditions; indeed, evaluation plays a crucial role in guiding changes in institutions, educational, and healthcare services (Vestman \& Conner, 2006; Ciucci, 2008; Ferrario, 2013).

Within this framework, the EduEval project ${ }^{4}$ focuses on the evaluation of adult education staff. It promotes exchanges among researchers and practitioners from the European countries involved, in order to gain better knowledge of the evaluation practices, procedures, and models of adult education staff. The aims of the project are, first, to identify both transversal and specific features of current evaluation practices in the countries involved; then, based on this analysis, to draw up guidelines to facilitate evaluators in carrying out their work;

\footnotetext{
${ }^{4}$ «Evaluation for the Professional Development of AdultEducation Staff». Project Number: 538743-LLP-1-2013IT-GRUNDTVIG-GMP; Grant Agreement Number: 2013-3800/001/003. This project has been funded with support of the European Commission. This document reflects the views only of the author, and the Commission cannot be held responsible for any use which may be made of the information contained therein. More information is available at: http//edueval.eu.
} 
and, finally, to define ideal training programmes for evaluators of adult education staff.

This paper discusses the first phase of the EduEval project, and, in particular, the outcomes of the Mobility Workshop, organized with the idea of developing the partners' mutual knowledge of the most representative evaluation practices currently used in European adult education staff. The six case studies are presented from a pedagogical perspective, in order to identify the transversal meanings and specific features that emerge from them. In the light of this analysis, the article explores how evaluation may sustain the work of adult education staff. Within the international pedagogical debate, it is crucial to identify the conditions that make evaluation an opportunity to learn from experience with the aim of enhancing the professional competence of adult education staff and of transforming their practices into "good practices" that go beyond accountability (Shaw \& Lishman, 1999; Rossi, Lipsey \& Freeman, 2004; Moss, 2005; Bezzi, 2007; Savignat, 2009).

\section{EduEval Mobility Workshop: the case studies}

The Mobility Workshop was held in Crete, Greece, in July 2014. Each partner was represented by a team of researchers and practitioners. In the months preceding the meeting, each team chose and prepared its own case study: the case selection criteria, salient features and framework for analysis and discussion were defined a priori and shared among the partners. During the meeting, each case was presented to the other partners at a plenary session. Then, it was analysed on the basis of the predefined criteria and discussed, first, in transnational discussion group sand, eventually, at another plenary session. The outcomes of the group discussions were recorded and shared among all partners.

The case studies described evaluation scenarios that the partners had chosen as representative of their evaluative practices, and that they considered significant in terms of type, modes, criteria, tools, potential, and limitations of evaluation put into practice. According to Panteia (2013) and Research voor Beleid (2010), the cases presented situations in which the evaluation of adult education staff was conducted by an "unofficial" evaluator: the work of this professional figure involved carrying out other functions alongside or together with evaluation. In addition it, there also were situations in which the evaluation of adult education staff was formally conducted by an "official evaluator," whose primary role was to carry out appraisals. The contexts in which the cases were set were highly diverse: a residential community for persons with disability (Milan, Italy); a prison (Bari, Italy); a training course for the staff of the Cretan Immigration Office (Greece); a training course for social workers on the dangers of cyberspace (Poland); the introduction of VALIDPACK in a series of 
European contexts as a tool for evaluating educator training (Latvia); the implementation of ISO 9001 in an educational centre (Spain).

This diversity immediately cast a light on two key pedagogical issues. First, it shows that evaluation practices are both widespread and pervasive in education and training contexts: evaluation does not seem to be confined to specifically planned and dedicated spaces and times, but it is intertwined with educational practices in a way that is often implicit. Thus, according to A. Rezzara, it is possible to state that evaluation is a key pedagogical dimension, which is an intrinsic part of all phases of the educational process, though it has traditionally been confined to specific times, such as the end of that process (Rezzara, 2000). Second, this diversity also reflects the variety of meanings and strategies that may be associated with evaluation in adult education contexts. Such variety, on the one hand, points out that evaluation is rooted in the specific context in which it takes place, and it is, therefore, closely related to particular work and thought traditions (Bisio, 2002). On the other hand, there is the risk that this variety causes fragmentation, which, as its most critical consequence, will not facilitate the development of pedagogical thinking about the evaluation practices, so that evaluation is relegated to habitual actions and procedures that are unrelated to the professional and training needs of the persons undergoing it (Shaw \& Lishman, 1999).

\section{The Case Studies: Representations and Meanings}

Without denying the many differences and specific features of the evaluation practices, it is of great interest to identify the main representations of adult education staff evaluation, and, in particular, the transversal meanings that were shared by the different contexts presented in the case studies. Our aim is not to come up with a univocal view of evaluation or a single "right" model to be approved by all. Conversely, as stated above, our goal is to develop an indepth reflection on evaluation practices, in order to identify its components and to reconstruct the meaning that it bears in the contexts in which it takes place. We expect that this analysis will advance our understanding of the impact of evaluation practices on educational contexts, and of how they may be deployed to strengthen these contexts.

Thus, a key transversal feature emerging from the case studies and our preliminary analysis of them at the Mobility Workshop is related to knowledge: evaluation is always conducted in relation to an "issue of knowing". In each case, one starts out from a condition of ignorance, while evaluation serves to develop knowledge. What is not known, that is to say, the objects or the situations to be evaluated, may be extremely different to one another. In the Bari case study, evaluation meant acquiring knowledge about the work of various figures who are involved in the re-education of prison inmates. In the Milanese case study, evaluation served to develop knowledge of how the community's 
educators worked with people with disabilities, while in the Latvian case study, evaluation enabled and delivered a process of getting to know the individual professional competences and skills of each member of the adult education staff. In the Polish case study, evaluation consisted in finding out how a particular training course for adult educatorsworked on the basis of the participants' feedback.In the Spanish casestudy, evaluation was focused on knowing and recognising the conditions that made a production process more efficient, while in the Cretan case study, evaluation implied a gradual gathering of knowledge that was built up within the educational situation itself, and was focused on how adult learners participated in the course, as well as on their "educational gains".

This need for knowledge, and the diversity of its objects, points up the question of the evaluative perspective and the quality of the knowledge produced in the process of evaluation. What is it that makes an evaluation, and therefore a knowledge-gathering, process valid and reliable? As it is well known, this is a longstanding and fundamental epistemological issue (Lichtner, 1999; Reggio, 2002). While it is beyond the scope of this paper to address it in depth, our set of case studies highlights a number of relevant aspects, which may contribute to stimulating reflection on the topic. If we consider evaluation as a process of knowledge acquisition, the question of validity seems to be related, in the first instance, to the possibility of making explicit the conditions, assumptions, methodologies, strategies, and instruments adopted by the evaluators, which may characterize the contexts in which the evaluation takes place. This essentially means to view evaluation as a practice that is situated within broader epistemological, cultural, and socio-material frameworks. As emphasized by the ecological paradigm and constructivist epistemology, the validity of a knowledge-gathering process may only be assessed by making explicit the assumptions (ontological, epistemological, methodological, ethical and pragmatic) underpinning it (Guba \& Lincoln, 1985; 1989; Denzin \& Lincoln, 2005; Mortari, 2007).

In relation to our own case studies, therefore, what characteristics of evaluation as a knowledge-acquisition process may we identify?

In the first place, the knowledge-gathering processusually means to introduce an external perspective on the situations or people to be evaluated. It seems that this perspective may be situated along a continuum that ranges from extraneousnessto proximity. In the Latvian and, partially, in the Polish case studies the evaluator did not know the educators being evaluated and was not familiar with (nor sought to be become familiar with) their professional contexts. In other cases, the evaluator belonged to the same institutional context as the educators, whose work was to be evaluated (the Milanese case study, for example) or as the figures in relation to whom he/she must activate processes of recognition and mutual familiarization (the Bari case study).In other contexts, the evaluator gradually got to know the educators themselves or their work, by sharing specific educational experiences with them (the Cretan case study). 
In addition, evaluators adopt particular methods and instruments to acquire knowledge about the objects or subjects of their evaluation. In this regard, the situations reported in the case studies featured a broad range of strategies, methods and instruments. They were codified and officially recognised, as in the Latvian case study; instruments and methods are well-established within social or educational research, as in the Polish and Greek cases, or they have been formalized into specific quality assurance procedures, as in the Spanish case. Relational strategies and instruments are strongly related to the specific features of the context in which the evaluation is being conducted and to the peculiar characteristics of the situations being evaluated, as in the Milan and Bari cases. In all the cases, evaluators' professionalism and expertise, as well as their educational/training and cultural backgrounds, along with the degree of recognition accorded to their role (official or unofficial), appeared to be closely related to the choice of the evaluation methods and instruments to be used.

A further aspect that emerges from the case studies is that knowledge derived from evaluation in adult education contexts is required to be useful. As observed by Bisio, usefulness is a key criterion to establish the value of a given evaluation (Bisio, 2002, p. 31). Therefore, the perspective from which the evaluator enters, or interacts with, the various situations is influenced by the reasons depending on which the evaluation is being undertaken, which are not only theoretical, but also practical ones. The case studies show that evaluation may be conducted, first, in order to address critical situations in which there is a clear or hidden dissatisfaction, or to address inefficiencies the service (Milan, Bari, Crete, Spain). Second, it is conducted to enhance professional performance of individuals (Latvia, Poland), teams (Bari, Crete, Milan) or, third, at the institutional level (Spain), in relation to standards to be attained or objectives to be reached. The individual or team awareness typically fostered by evaluation across all the contexts had always had pragmatic consequences: it could lead to some change in subjects' attitudes, in how they exercise their role and functions, in how they carry out their daily professional activities, and in the ways of designing and delivering educational, training or evaluative interventions.

To sum up, the position of the evaluator in relation to the object of the evaluation (role, perspective, training, expertise), the chosen methods and instruments, the motivations - either institutional, political, educational, or economic - driving the implementation of an evaluation process, the expected outcomes, as well as the usefulness of the process at stake appear to have great impact, in different ways, on the quality of the knowledge that evaluation produces.

However, this is not the whole picture. There is another dimension of evaluation that strongly emerges from the case studies. Particularly, as a consequence of what we have observed so far, evaluation is not only a matter of knowledge, but also of power. Power is here understood as having the double meaning highlighted by Foucault in his works. On the one hand, there is the 
"power that produces", which makes someone else do something, which brings about change, which organizes persons, objects, times and spaces, and which includes or excludes (Foucault, 1975). On the other hand, there is the power that is closely connected to knowledge: a power that is exercised to obtain knowledge and which, in turn, generates knowledge in its various forms (awareness, but also classification, for example) (Foucault, 1969; 1971; 2003). The knowledge produced by evaluation has power. As it has been outlined, it has pragmatic consequences: it can have impact either on the professional life, or on the existence of the person involved in the evaluation process, thus causing effects such as individual empowerment (Gheno, 2002; Righetti, 2002) and/or irreversible organizational and institutional changes (Amietta, 2002). Evaluation "makes something be done", and at the same time it augments forms of knowledge that may change the behaviour, function, or the position of individuals within a work context.

In the case studies in analysis, different aspects of the dimension of power were represented. Power was inscribed in the role of the evaluator. In the Milanese case study, the responsible for the functioning of the service and the wellbeing of its users exercised his power via an evaluation, whose outcomes would modify the composition of the educational team, as well as the team members' modes of daily work. In the Latvian, Spanish or Polish cases, power was inscribed in the role of official evaluator and as such those detaining it were authorized to engage in a defined course of action, which involved asking questions and activating specific procedures. In the Greek case, the power exercised by the trainer allowed her to involve people in a given training activity in order to observe dynamics, produce reflection, and promote learning. In any case, the exercise of evaluation is never neutral, unless, of course, it fulfils a purely celebratory function, aimed at confirming the status quo in the evaluated situation.

The fact that evaluation generally hasan impact, however, is borne out by the affective dynamics that it sets in motion. Especially, though not exclusively, when evaluation is imposed, it can give rise to dynamics of resistance or refusal. Evaluation forces us to come to terms with the existing context; to accept comparison with analogous situations that are more effective or efficient than our own, or with prescribed standards; to address/impact with our limitations and challenges in carrying out a professional duty; to recognise training needs at the individual and team levels. Evaluation poses questions and challenges, and, for this reason, it may be defined as at horny and complex experience (Bellotto, 2002). Our case studies show that the need for the evaluator to take into account relational dynamics, feelings and emotional reactions set off by the evaluation, is more explicit when the evaluation involves teams of professionals, and when it leads to key changes at the professional and existential levels. The Milanese case study is emblematic in this sense. Conversely, when the evaluation is focused on the professional development of the individual educator (Latvian 
case study), or is experienced as the implementation of individual and team efforts aimed at enhancing the quality of production processes (Spanish case study), the emotional dimension is either not made explicit or is not viewed as requiring particular attention.

With regard to affective dynamics, the case studies present situations in which the level of involvement on the part of the evaluator, individuals, and team was highly variable. It seemed to depend on the person's belonging in the situation under evaluation (greater or lesser extraneousness), on the object of the evaluation (the professional competences of individuals, as in the Latvian case study, or the team working, as in the Milanese case), on the subjects being evaluated (individual professionals or the work group as a whole), or on the motivations for and objectives of the evaluation process itself (enhancing personal development and training, introducing changes at the organizational level or in the working methods of a team, compliance with particular standards of production or performance). In any case, emotional reactions and affective dynamics, when made explicit, may be either amplified or mitigated by the atmosphere that the evaluator contributes to creating or modifying during the evaluation process.

Hence, the cases in question represent evaluation as a process that is closely related to training at the levels of individual, group, and overall education/ training context. This is not only because evaluation is a phase of the training process, as is evident in the Greek and Polish case studies, but also because it displays considerable training potential in its own right by eliciting knowledge and change. This is clear in all the case studies, when the evaluation process concerned individual educators (Latvian and Polish cases) and when it concerned a group, work context, or institution (the Greek, Milanese, Bari, Spanish and Polish case studies). Evaluation is thus represented as a practice that can activate complex learning processes, at the individual, group or institutional levels (Beeby, 1977; Wolf, 1987; Bisio, 2002); processes that, as discussed above, can affect the behaviour of individuals and groups in their work contexts. Such processes are seen, in most of the cases reported, as processes of awareness raising, which at times can be painful and conflictual (as in the Milan and Bari cases), that is as processes which imply to learn from experience (Boud, Keogh \& Walker, 2000; Schon, 1991; Mortari, 2003). Thus, albeit in different ways, in some cases more explicitly and in others more implicitly, evaluation appears to be represented as learning (Hadji, 1992; Bertolini, 1999; Pandolfi, 2012). However, evaluation is not always guaranteed to yield a learning effect: in the case studies, in particular the Milanese, Bari, Greek, and Polish scenarios, learning was a problematic aspect, which could be developed but which could also be avoided. The fact that both evaluators and evaluated experienced the evaluation process as challenging (in the Milanese, Bari, Greek and Polish cases) stand witness to this theory. 
This leads us to ask what conditions are required to ensure that the evaluation process will be a learning process. Based on the case studies, it would seem that there are two conditions that influence the learning effect of evaluation. On the one hand, we have conditions that are external to the evaluation process per se; these include the reasons why the evaluation should be conducted, the institutional context in which it is taking place, the range of instruments and procedures available to the evaluator, and accepted in the context, the official or unofficial status of the evaluator. On the other hand, there are conditions that are internal to the process. These include the openness of the participants to the process, the particular instruments and procedures that the evaluator has chosen, the evaluator's modes of communication, his/her capacity to create a positive setting and atmosphere, and his/her ability to stimulate reflective processes, but also the capacity of both evaluator and institution to maintain any changes activated.

The final outcome of the evaluation process in terms of educational or selfeducational opportunities (Righetti, 2002) depends on the combination of all these factors. This combination seems difficult to plana priori: in fact, it delineates during the evaluation process itself, and, therefore, it requires the evaluator's attention, in terms of looking for ways to provide the conditions most favourable to educational outcomes, especially if the aim of the evaluation process is also, if not primarily, educational. Thus, the evaluator is required particular awareness, a particular focus, and particular competences that have a distinct pedagogical character. However, as the case studies have illustrated, both the evaluators and the adult education service as a whole may not be fully aware of the need for, or fully in possession of, these pedagogical resources.

\section{Conclusions}

The pedagogical reflection on the representations of evaluation in our case studies suggests that evaluation is a multi-faceted phenomenon. In accordance with pedagogical literature, the reported practices reflect multiple meanings of evaluation, some of which are contradictory and ambivalent. In the case studies, these means dynamically relate to one another in a peculiar way that was partly determined by the unique and original situation in which the evaluation was taking place.

Our reflection has shown that the key dimensions of evaluation are knowledge and power: evaluation stimulates knowledge processes, because it has the authority to do so and this knowledge, in turn, produces effects in the people and contexts involved. Knowledge and power may - the outcome is never a given - combine to generate educational and self-educational effects: in this sense, we may say that evaluation processes have implicit educational potential. This raises the issue of awareness of this potential, both on the part of the organizational contexts in which the evaluation processes take place, and on 
the part of the evaluators who conduct these processes. It also prompts us to explore the conditions required to make evaluation processes become learning processes for individual staff members, teams, and the overall adult education context.

To address these questions is crucial if we are to answer the research question from which the EduEval project stems: can evaluation be a way to enhance the work and professional competence of adult education staff? The current reflection on six case studies, though far from providing definitive solutions, allows us to hone in on certain conditions, which may be the object of further pedagogical enquiry, and which are key to making evaluation a valuable resource for adult education staff.

In the light of the contexts in which adult educators work, it seems critical to ensure that the outcomes of evaluation processes may be reflected on together with the participants, in order to identify practical ways for the individual, team, or institutional to support the changes prompted by the evaluation outcomes. This action is important whatever the aims of the evaluation are: implementing standard organizational procedures, making staff performance more competitive, complying with quality standards, sustaining or enhancing the educational and even evaluative competences of individual staff members, etc. If the knowledge, reflection, affirmation of current abilities or experimentation with new skills elicited by evaluation is not followed up in the everyday working lives of those who have experienced or tested them in the course of the evaluation process, there is a danger that evaluation will only be self-serving and will fail to make any significant contribution to supporting educators in their daily work. One of the conditions on which to work, from a pedagogical perspective, is the promotion of pedagogical and educational awareness in the institutional contexts in which evaluation is conducted, in order to implement processes of critical reflection.

Concerning the figure of the evaluator, reflection on the current case studies suggests that he/she must possess pedagogical competence relative to both the organization and the conduction of evaluation processes, in particular, the general and specific competences previously recommended for evaluators by Research Von Beiled. Thus, it is crucial for the evaluator to be able to: chose modes of communication and instruments that are appropriate for specific persons and situations; identify, monitor and manage the relational and emotional dynamics of work groups, as well as the relationship between the team, individual staff members and the evaluator him/herself; stimulate processes of critical reflection on professional experience; mediate between the work context and individual staff members, so as to activate or reinforce the pervasive pedagogical awareness required to transform the outcomes of evaluation into effective change.

Taken all round, our reflection so far suggests that a pedagogical culture, which views evaluation in the light of the complexity of meanings attributed to 


\section{SOCIETY. INTEGRATION. EDUCATION. Volume IV}

it and the complex variety of practices in which it is implemented, represents a goal to be pursued, at a general level, in order to sustain the work of adult education staff. A valid starting point could well be to develop pedagogical thinking around the figure and role of the evaluator, mapping out the meanings and practices of evaluation, pointing out its problematic aspects and, in the end, identifying the professional competences that characterise evaluators of adult educators, including designing ad hoc training programmes for them. A task that the EduEval project is in the course of accomplishing.

\section{References}

Amietta, F. (2002), Valutare i processi formativi: il valore aggiunto per l'organizzazione. In Bisio C. (2002) (Ed), Valutare in formazione. Azioni, significati, valori (pp. 174-186). Milano: FrancoAngeli.

Beeby, C. E. (1977). The meaning of evaluation, Current issues in education, 6, 66-78.

Bellotto, M. (2002). Valutare la dinamica del gruppo di formazione. In Bisio, C. (Ed), Valutare in formazione. Azioni, significati, valori (pp. 129-150). Milano: FrancoAngeli.

Bertolini, P. (1999), La valutazione possibile. Firenze: La Nuova Italia.

Bezzi, C. (2007). Che cos'è la valutazione. Un'introduzione ai concetti, le parole chiave e $i$ problemi metodologici. Milano: Franco Angeli.

Bisio C. (2002) (Ed), Valutare in formazione. Azioni, significati, valori. Milano: FrancoAngeli.

Boud, D. et al. (2000) (Eds), Reflection: Turning Experience into Learning. New York: Nichols Publishing Company.

CEU (2000), Memorandum sull'istruzione e la formazione permanente. Retrieved from http://archivio.pubblica.istruzione.it/dg_postsecondaria/memorandum.pdf

CEU (2008). Council conclusions of 22 May 2008 on adult learning. Official Journal of the European Union, 6.6.2008, C 140/10 - C 140/13.

CEU (2011). Council Resolution on a renewed European agenda for adult learning. Official Journal of the European Union, 20.12.2011, C 372/1 - C 372/6.

Ciucci, F. (2008). Valutazione delle politiche e dei servizi sociali. Partecipazione, metodo, qualità. Milano: Franco Angeli.

Denzin, N. \& Lincoln, Y. S. (2005) (Eds), Handbook of Qualitative Research. Thousand Oaks: Sage Publication.

Ferrario, P. (2013). Politiche dei servizi sociali. Strutture, trasformazioni, legislazione. Roma: Carocci.

Foucault, M. (1975), Surveiller et punir. Naissance de la prison. Paris: Gallimard.

Foucault, M. (2003), Le pouvoir psychiatrique. Cours au Collège de France 1973-1974. Paris: Gallimard.

Foucault, M. (1969). L'archéologie du savoir, Paris: Gallimard.

Foucault, M. (1971). L'ordre du discours. Paris: Gallimard.

Gheno, S. (2002). Valutare l'empowerment nella formazione. In Bisio C. (2002) (Ed), Valutare in formazione. Azioni, significati, valor (56-77). Milano: FrancoAngeli.

Guba, E. G. \& Lincoln, Y. S. (1985), Naturalistic Enquiry, Newbury Park, California; Sage Publication.

Guba, E. G. \& Lincoln, Y. S. (1989), Fourth Generation Evaluation, Newbury Park, California: Sage Publication.

Hadji, C. (1992), L'évaluation des actions educatives, Paris: Press Universitaires de France. 
Lichtner, M. (1999), La qualità delle azioni formative. Criteri di valutazione tra esigenze di funzionalità e costruzione del significato. Milano: FrancoAngeli.

Mortari, L. (2003). Apprendere dall'esperienza. Il pensare riflessivo nella formazione, Roma: Carocci.

Mortari, L. (2007), Cultura della ricerca e pedagogia. Prospettive epistemologiche. Roma: Carocci.

Moss, P. (2005), Theoretical examination of quality. Early Education \& Development, 4, 405420.

Pandolfi, L. (2012), Valutare servizi educativi. Un'introduzione. Bari: Pensa Multimedia.

PANTEIA (2013). Developing the adult learning sector: Quality in the adult learning sector. Retrieved from http://ec.europa.eu/education/library/study/2013/adult-quality_en.pdf

Reggio, P. (2002), La valutazione qualitativa nella formazione. In Bisio C. (Ed), Valutare in formazione. Azioni, significati, valori (pp. 220-246). Milano: FrancoAngeli

Research voor Beleid (2010). Key competences for adult learning professionals: Contribution to the development of a reference framework of key competences for adult learning professionals. Project number B3542. Zoetermeer: Research voor Beleid.

Rezzara, A. (2000), Pensare la valutazione. Pratiche valutative scolastiche e riflessione pedagogica. Mursia, Milano.

Righetti, E. (2002). La valutazione riflessiva: autovalutazione e apprendimento. In Bisio C. (2002) (Ed), Valutare in formazione. Azioni, significati, valori (78-93). Milano: FrancoAngeli.

Rossi P. H., Lipsey M. W. \& Frieman H. E. (2004), Evaluation: a Sistematic Approach. Thousand Oaks, CA: Sage Publication.

Savignat P. (2009), Évaluer les établissements et les services socieaux et medico-socieaux. Des savoir-faire à reconnaître. Paris: Dunod.

Schön, D. A. (1991), The Reflective Practitioner. London: Temple Smith [1983].

Shaw I. F. \& Lishman J. (1999), Evaluation and Social Work Practices, London: Sage Publication.

Striano, M. (2010), L'inclusione come progetto di sviluppo sociale nello scenario europeo. In Striano, M. (Ed), Pratiche educative per l'inclusione sociale (pp. 9-29), Milano: FrancoAngeli.

Vestman, O. K. \& Conner, R. F. (2006). The relationship between evaluation and politics, in Shaw I. F. et al. (2006). The Sage Handbook of evaluation: politics, programs and practices (pp. 225-241), London, CA: Sage Publication.

Wolf, R. M. (1987), The nature of educational evaluation, in Wolf, R. M. (Ed.), Educational evaluation: the state of the field, international journal of educational research, 11 (1), 7-20.

www.edueval.eu 